\title{
LAYOUT AND MATERIAL FLOW OPTIMIZATION IN DIGITAL FACTORY
}

\author{
Centobelli, P.*,\#; Cerchione, R. ${ }^{* *}$; Murino, T. ${ }^{*} \&$ Gallo, M. ${ }^{* * *}$ \\ * Department of Chemical, Materials and Industrial Production Engineering, \\ University of Naples Federico II, Piazzale Tecchio 80, 80125, Naples, Italy \\ ${ }^{* *}$ Department of Industrial Engineering, \\ University of Naples Federico II, Piazzale Tecchio 80, 80125, Naples, Italy \\ ${ }^{* * *}$ Dipartimento Scienze Giuridiche ed Economiche (Legal Sciences and Economics), \\ Pegaso Telematic University, Via Vittoria Colonna, 14, Naples, Italy \\ E-mail: piera.centobelli@unina.it,roberto.cerchione@unina.it,murino@unina.it, \\ mose.gallo@unipegaso.it ( ${ }^{\#}$ Corresponding author)
}

\begin{abstract}
The ability to realize customized products, in particular for engineering-to-order companies, is a key factor in order to be competitive in modern market without incurring any additional cost and respecting customer lead time. In this ever-changing environment the layout optimization is a fundamental issue requirement, hence the development of a virtual layout, according to the Digital Factory concepts, can be very useful to identify and to solve potential problems during the planning phase, before realize it. The main aim of this paper is represented by the proposal of a layout reconfiguration and a technological solution for the parts feeding system of the industrial plant analysed in order to reduce the production lead times.

In the first phase, an overview of the Digital Factory applications is provided. In the second phase, after data analysis in an Italian manufacturing company, a simulation model has been designed and tested using Simio simulation software. Simulations results concerning production and queue times obtained from different orders have been compared with actual configuration data.

Research results indicate that the surveyed company has had an improvement in terms of reduction of waiting times and increase of customers satisfaction due to total production lead time reduction.

(Received in May 2015, accepted in November 2015. This paper was with the authors 5 months for 1 revision.)
\end{abstract}

Key Words: Digital Factory, Layout Optimization, Manufacturing and Simulation Model, 3D Simulation

\section{INTRODUCTION}

In the past customer demand was more stable and the companies less subject to foreign competition than today [1]. Indeed in modern manufacturing the demand for customization and high-mix is growing [2].

The time to market has been reduced; customers have more different requests and ask for high quality finished goods but also at low prices. This is the scenario of a new world in which factories had to work and fight to predominate over the other competitors.

In today's competitive global marketplace, the use of strategies to absorb fluctuations in demand, to develop and introduce new products in the production planning using existing facilities are seen as important competitive issues [3].

All these factors can be considered as responsible of a new kind of manufacturing systems, which are characterized by flexibility and reconfigurability [4]. An important issue concerns how much flexible the layout should be in order to face the possible future changes in product demand and product mix. Nowadays the choice of the right facility layout for firms is a real strategy. The improvement of flexibility has become increasingly important as a method to achieve competitive advantage in manufacturing companies [5-8]. Therefore this 
decision should be done carefully, only after an in-depth analysis of the detailed operational requirements of the firm they refer, including the layout of the plant.

The layout planning design is a complex activity involving the optimization of the positions of machines, transportation systems and workstations. Nowadays, the layout optimisation, as well as re-layout optimisation, has been made more efficient by using information technology tools, e.g. simulation software.

The use of simulation techniques for the design and optimisation of production processes and system is known as Digital Factory [9]. The Digital Factory includes both the products development, e.g. developing 3D models, and the production planning and systems. It is common practice to use digital product development tools in companies, and the scientific literature is full of published studies. However the focus of this paper is on the production planning aspect of Digital Factory concept. The Digital Factory concept allows designing, evaluating, monitoring and controlling the whole manufacturing system using the $3 \mathrm{D}$ simulation in order to create virtual 3D layout that represent the real facility. The development of a virtual layout can be very useful to identify and to solve potential problems during the planning phase, before realize the factory [10].

Potential problems could be related to the material flows and handling, fundamental key factors for the design of a functional system. According to Wy et al. [11] simulation can be used to analyse how system performance is affected by the layout configuration, the number and the type of material handling system used.

The 3D visualization allows representing aspects impossible to represent in a $2 \mathrm{D}$ way, e.g. the people and material flows in the factory layout.

Simulation tools are largely used to check the system behaviour before building it and invest in human resources, instruments, robotic systems or layout reconfiguration. Using this approach, firms can save large amounts of money.

This technology provides a big support for the decision-making process by means of complete representation of the manufacturing process as well as manufacturing layout, enabling them to inspect and walk around the rendered factory plant 3D model.

The paper explores one of the several aspects assessed by the Digital Factory implementation approach. In the Digital Factory concept, the virtual models are necessary in order to design and explore factories layout, using CAD 3D-factory models. According to Westkämper [12] simulation and 3D-visualisation are essential methods and tools for a proper implementation of Digital Factory.

In this paper a new layout configuration for the investigated manufacturing firm has been evaluated developing a 3D model. The object-oriented simulation software Simio Simulation has been used to simulate the new process layout in which different department are connected through a conveyor system, which impact many manufacturing parameters, i.e. set-up and run times, lots size, queue times and manufacturing cost. This software assists experts to evaluate the effects of this proposal and to obtain information about factors which influence lead time performances. Research results demonstrate that a small investment related to reconfiguration implies a high lead times reduction.

The remainder of this paper is organized in six sections: after this introduction, in the second section the framework is described; the methodology is analysed in the third section; the fourth section deals with problem definition; the simulation model results are reported and discussed in the fifth section; finally, conclusion and implications are in the sixth section.

\section{FRAMEWORK}

The Digital Factory approach is based on the integration of methods and tools to plan and test the product development and its related production process in the design phase [13]. 
Already in the 2000, Wörn et al. [14], introduce the Digital Factory concept and identify the several processes that this new innovative approach to factory automation integrates: product and production process development and optimisation, production facilities design and improvement, as well as simulation concerning production planning and control.

Some of the typical simulation applications [13] in the Digital Factory are:

1. Production control and simulation of production flow,

2. Line balancing of assembly processes,

3. Simulation of material handling systems,

4. Industrial robotics work cells,

5. Ergonomics evaluation through simulation of human resources,

6. Design, validation and optimisation of Digital Factory layout.

Depending on the particular goal of the simulation different tools and levels of detail are required.

As concern the production flow planning and control, mainly discrete event simulation is applied. The continuous interaction between factory planning and factory operation is required in order to implement and verify the operations planned in the virtual model in the real factory [15]. Using material flow simulation technology is possible calculate the buffers dimension as well as evaluate key performance indicators, e.g. total processing time or setup times minimization $[16,17]$.

Realize an assembly line able of producing the desired product is the main aim of every company [18]. The assembly line design in turn includes three problems, the layout configuration definition, the selection of the right equipment and the balancing of the assembly line [19]. The assembly line balancing consists in the assignment of operations to workstations in order to reduce the idle time satisfying precedence constraints [20].

In manufacturing systems the materials handling technology used is very important in order to reduce the cycle-time. Time spent for materials handling (raw materials and work in process) is considered waste. For this reason the feeding system should be designed more functional as possible and it depends on several factors, such as the lot size, the number of components and the distance between warehouses and assembly lines [21].

In the last years, the 3D simulation is largely employed also for robotic work cells, to verify the behaviour of robots in flexible manufacturing cells [22]. The simulation modelling of robots was born to analyse the interactions of robots with the other objects of the manufacturing cell, including robots, and to overcome the problem of possible collisions simulating the trajectories [23].

In recent years industrial plant safety focuses on human-factors engineering, also known as ergonomics, and main specifically on the study of designing equipment and devices that fits human bodies and cognitive abilities monitoring workers operating conditions. Also the scientific community is moving in this direction. Recent studies showed that the improvement of working conditions improves product quality and plant productivity [24-26]. A new methodological framework has been proposed in order to link assembly systems design and workplace ergonomics considerations optimizing both productivity and quality of workers workspace [27].

Finally there is the design, validation and optimisation of Digital Factory layout. As well as design and location of organizational facility, the industrial layout design is a critical aspect in order to maximize both the efficiency and the effectiveness of operations system [28]. For example, Discrete Event Simulation (DES) modelling of a digital manufacturing system can be employed to analyse the system's production performance, layout, ergonomics and robotics issues, through $3 \mathrm{D}$ motion simulation $[12,13]$.

Internal transportation costs minimization [29] is one of the most common criteria used for layout planning and design, as well as productivity maximization [30]. 
There are several scientific papers in literature focusing on facilities planning simulation [31-38]. The applications could be deal with the creation of a new factory or the improvement of an existing one. In the last case, e.g. the production capacity or the layout should be changed and optimised according to a new production programme. Therefore it is necessary to reduce the planning time [39] in order to be more responsive. As a result, it is necessary reduce the production planning phase, mainly related to facilities, analysing all the relevant data in order to understand potential savings and costs reductions.

The focus of this paper is on the optimisation of the materials flow improving the layout facility of the firm investigated.

For this paper the potential of the Digital Factory tool is very high. This accelerates the planning process by showing workflows, as well as logistics and production sequence simulation. The aim is to make a computer model of production plant in order to evaluate and improve production according to technical, logistical and commercial criteria.

\section{METHODOLOGY}

According to the Toyota Production System (TPS), and the more generic Lean Manufacturing principles, typically in a manufacturing system seven types of waste can be identified: high inventory levels, overproduction, empty running, delays, unnecessary processes, defects and materials handling. Many of these are caused by a non-functional layout. A well-designed layout minimizes the material-handling flow, transportation distances, and movement of people within the industry, making the manufacturing system more productive and efficient. The layout has to be designed in such a way that the products move between the various areas in the simplest way possible.

Generally the study of plant layout is made for the realization of a new product production or the improvement of an existing facility. Possible changes of products characteristics, customers demand, local regulation related to workers operating conditions (ergonomics) or environmental issues required a re-planning of the layout facility. In any case modelling and simulation techniques enable dynamic analysis to ensure that plant design problems and potential wastes are discovered before the company realize the plant.

The most used technique for the study of the layout, was introduced in 1973 by Richard Muther and it is called Systematic Layout Planning (SLP). It can be divided into three basic phases:

- careful and comprehensive data collection,

- evaluation of possible solutions and their performance,

- improvement and selection of the best solutions.

The methodological approach followed in this paper (schematically shown in Fig. 1) has been adopted by the framework proposed by Muther.

\section{PROBLEM DEFINITION}

The manufacturing company investigated operates in southern Italy. It produces six different type of insulating coatings in "engineering-to-order" environment. After an in-depth analysis, has been recognized that several aspects should be optimized in the factory layout in order to reduce lead-times and both material and resources flow. One of the main efficiency of the production process analysed is related to the time spent handling work in process between service stations. Currently the work in process is loaded in buffers next to each workplace. When the worker of the downstream work centre is available they are transported from one station to another without considering neither the batch size nor the production plan. Therefore the work aims to analyse the improvements obtainable from both layout re-design 
and the introduction of a belt-conveyors system in order to which ensures continuity to the production line, reducing the idle time and resources flow. This new scenario will be simulated using the simulation software Simio.

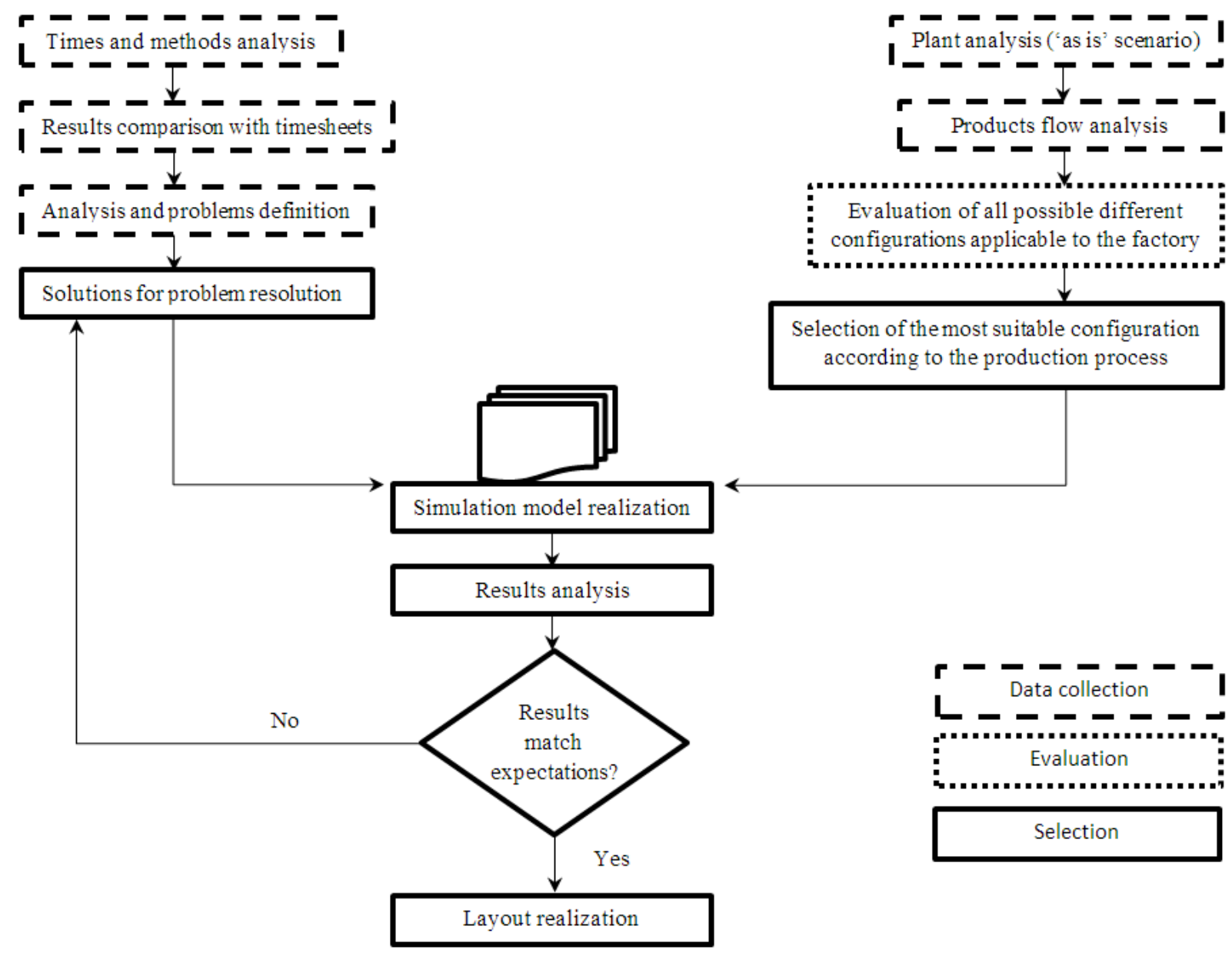

Figure 1: Flow-chart of the methodology.

\subsection{Data collection: times and methods analysis}

An accurate and direct in-depth analysis of the times and methods has been conducted by analysing the time required for each product in each work centre. The $3 \mathrm{D}$ model requires several essential inputs for the simulations, e.g. the entities, the workstation typology, the setup times, the processing times, the operations routing and so on.

\subsection{Selection of most suitable configuration}

According to the production process, the industrial plant can be configured as a process layout. The production process is rather simple, not technologically advanced machines are required. Another simplifying aspect is that all the products follow the same processing cycle although the processing time required by each product results to be different. The first step is to analyse the processing cycle from a qualitative point of view (diagram of the operational process) of each product that has been represented in Table I.

The production process is rather simple. However, the processing times of the products are different. The processing times differences are related to the complexity of each component. The production process starts in the work centre W1. When the established lot size is reached, the lot passes in the second work centre. Actually the work in process materials handling is achieved thanks to an operator of the summit station that places the lot 
in the buffer of the downstream station. It is clear that this is a double waste of time: the operator inactivity due to material handling and the time spent waiting for the remaining lot in the bottom station. Since the workers check all the products, non-conformities, in terms of quality, are forthwith identified and corrected. This allows considering the absence of material scraps and rework processes.

Table I: Product flow diagram (Oi: Operations required; Pi: $i^{\text {th }}$ product).

\begin{tabular}{|c|c|c|c|c|c|c|c|}
\hline & $\mathrm{Pi}$ & $\mathrm{P} 1$ & $\mathrm{P} 2$ & $\mathrm{P} 3$ & $\mathrm{P} 4$ & $\mathrm{P} 5$ & P6 \\
\hline & $\begin{array}{c}\text { Materials } \\
\text { Warehouses }\end{array}$ & $\nabla$ & $\nabla$ & $\nabla$ & $\nabla$ & $\nabla$ & $\nabla$ \\
\hline \multirow{4}{*}{ Oi } & $\mathrm{O} 1$ & 9 & i & q & 9 & 9 & 9 \\
\hline & $\mathrm{O} 2$ & 9 & & & 1 & & \\
\hline & $\mathrm{O} 3$ & & & & & & \\
\hline & Shipping Area & $0^{\prime}$ & o & O & o & o & O \\
\hline
\end{tabular}

In each case, the objective of the layout will be to have a progressive flow with a minimum of returns, and to have available consecutively the operations related to large flux intensity. The Hollier algorithm represented in Table II allows determining the right position of the machinery in order to make the route as linear as possible.

Table II: Elaboration of from/to chart (all data has been opportunely weighted and normalized).

\begin{tabular}{|c|c|c|c|c|c|c|}
\hline \multicolumn{2}{|r|}{ TO } & 1 & 2 & 3 & $\sum$ From & $\begin{array}{c}\sum \text { From } / \\
\sum \text { To }\end{array}$ \\
\hline \multirow{3}{*}{ 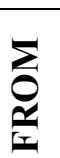 } & 1 & 0 & 0.5 & 0 & 0.5 & $\infty$ \\
\hline & 2 & 0 & 0 & 0.5 & 0.5 & $0.5 / 0.75=0.66$ \\
\hline & 3 & 0 & 0.25 & 0 & 0.25 & $0.25 / 0.5=0.5$ \\
\hline & $\sum$ To & 0 & 0.75 & 0.5 & 1.25 & \\
\hline
\end{tabular}

Analysis shows that the optimum work station disposition of the units is 1-2-3. A hybrid "U" layout turns out to be particularly suitable for products that are on the production line; in each area there will be machines and tools to perform the same operations.

\subsection{Software modelling and simulation}

In the model developed the machines are disposed according to a hybrid layout as the products are different but follow the same cycle, so "being the differences" rather small it can be assumed a layout in which the machines are grouped by bringing in a single department all machining of the same type. It is also chosen to dispose the machinery in the shape of $U$.

In the Fig. 2 a $2 \mathrm{D}$ view of the plant is provided where the three manufacturing departments and the shipping area are cleat and appropriately highlighted.

This configuration is particularly suitable as it allows:

- closeness between workstations,

- flow continuity,

- increased communication, flexibility and control,

- reduction of the maximum queue during processing and idle time.

The objective to be achieved is the minimization of the cost due to materials handling. 


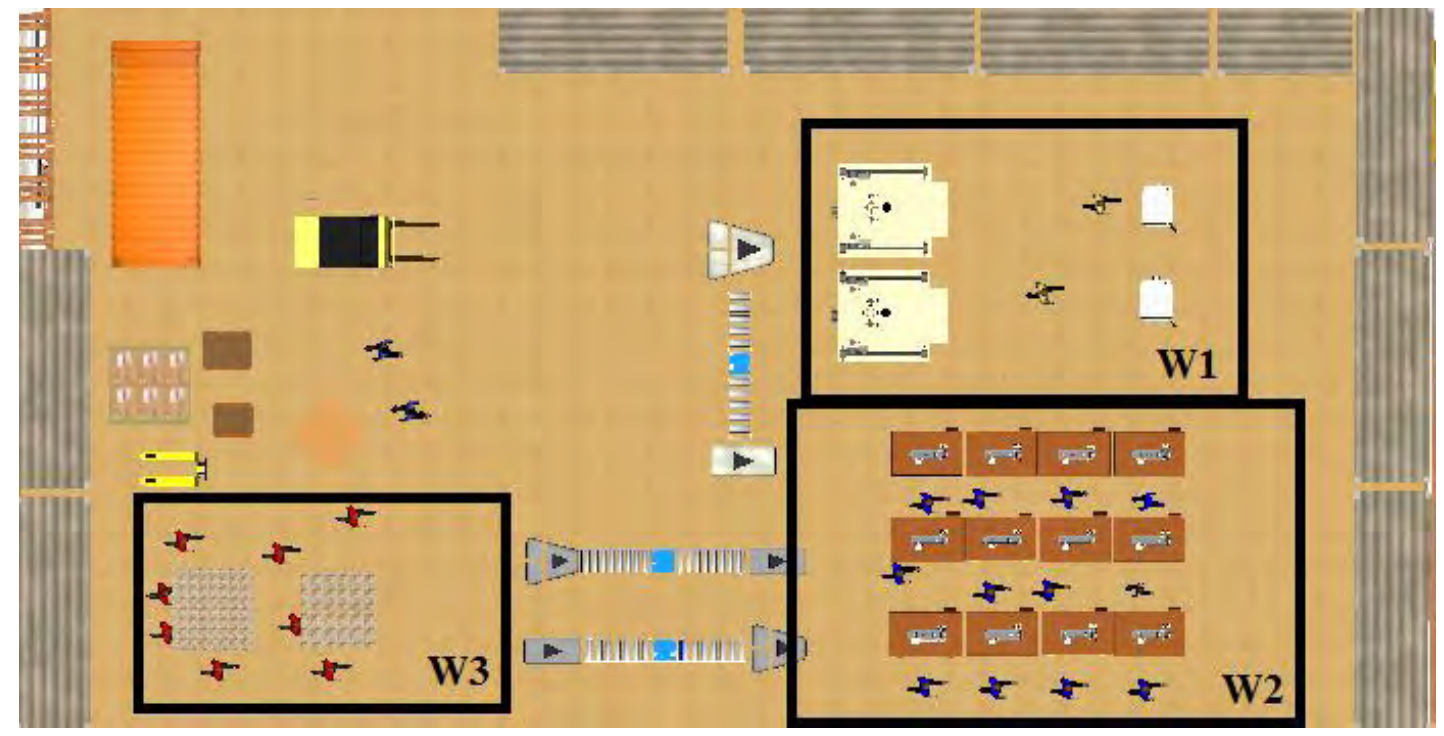

Figure 2: 2D-view of the layout designed through the simulation software

(W1: Work centre 1, W2: Work centre 2 and W3: Work centre 3).

The main aim of 3D simulation is establish if the layout reconfiguration and the conveyor system implementation in the manufacturing system analysed lead to an improvement in terms of performances as well as analyse the human-machines interactions. In this software, due to complete the simulation is necessary to insert several input data. The 3D model (Fig. 3) represents the manufacturing factory planned; it simulates the production process, the automated belt conveyors carrying the pieces from one station to the buffer of the work centre immediately downstream of the production cycle, the storage and shipping area.

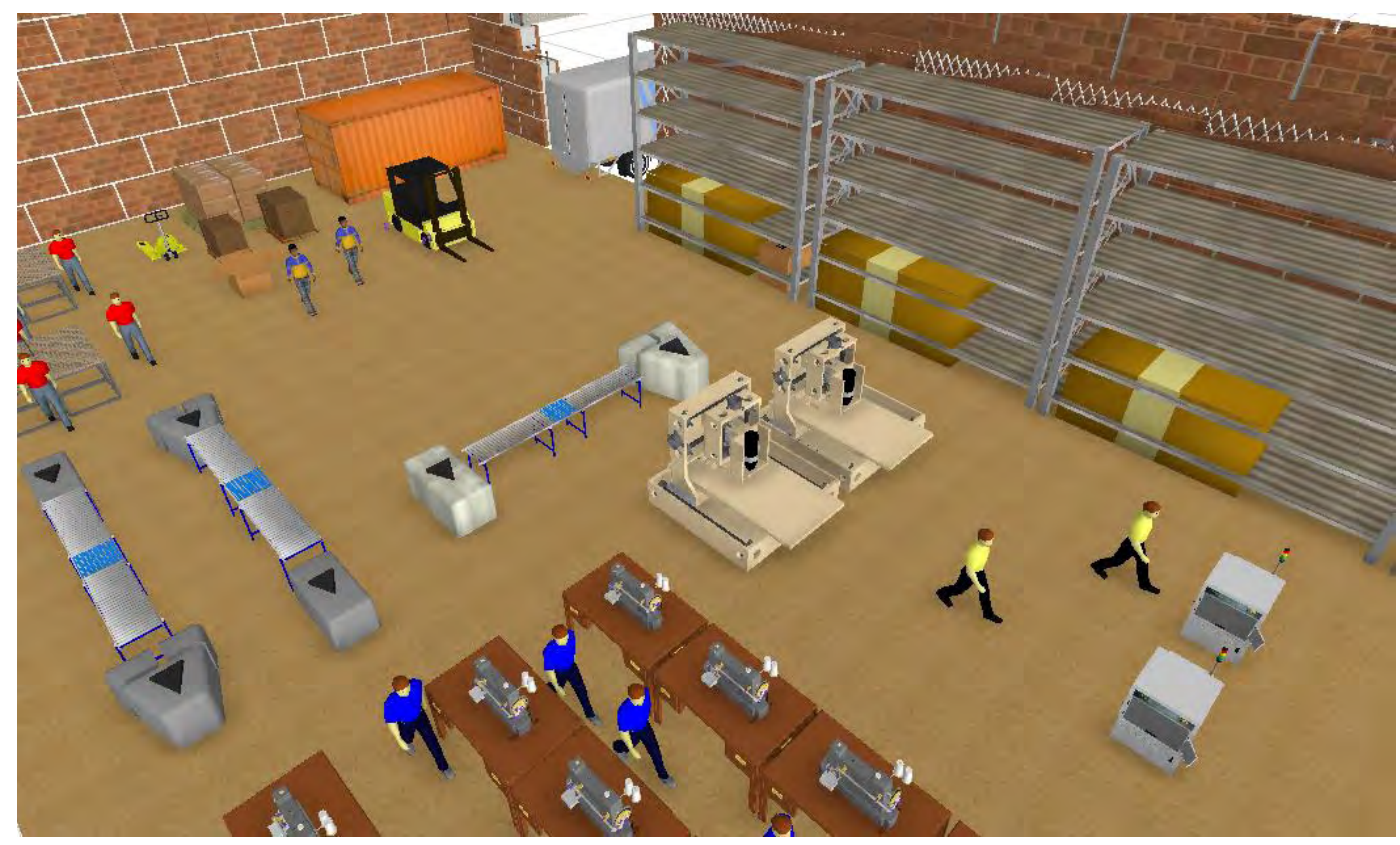

Figure 3: 3D-view of simulation model.

\section{SIMULATION MODEL RESULTS}

In this section will be reported and analysed the results obtained from the eleven simulation runs. The data required to compare the results of the simulation and the real data are the following: 
- $t_{p, i, j, k}$, which represents the effective processing time required by the product $k$ for the operation $i$ on machine $j$;

- $t_{s, i}$, time required to set the equipment and prepare the materials required to perform the operation $i$

- $t_{q, i}$, waiting time of WIP before operation $i$.

The tables III, IV and V summarize the results obtained by the simulation. The compared results, appropriately parameterized with respect to a $k$-factor, are described and discussed below.

After completion of the simulation model and insertion of the required data eleven simulation runs start. Different scenarios have been simulated, accordingly to the different company orders and the results have been compared with real data.

Table III summarizes the cumulative time spent by work in process in each work station and machine. On the other hand, Table IV reports a comparison between simulation results related to production times and real data. The last column contains the percentage value due to time reduction $\left(\varepsilon_{R}\right)$.

Table V contains the comparison between real and simulated scenario. In all cases the firm obtains a time reduction that ranges from 8 to $1 \%$.

Finally Fig. 4 reports the total time required in 'as is' scenario $\left(S_{R}\right)$, the total time required in the new scenario simulated $\left(S_{S}\right)$ and the time savings expressed in hours.

\begin{tabular}{|c|c|c|c|c|c|c|c|c|c|c|c|c|c|c|}
\hline & & & & & & & & & \\
\hline
\end{tabular}

Figure 4: Simulation results expressed as the total time required in 'as is' scenario $\left(S_{R}\right)$, the total time required in the new scenario simulated $\left(S_{S}\right)$ and the time savings (in hours).

The new system performances are definitely better than the real ones. In particular, the introduction of the conveyor system allows to reduce the waiting time spent for the batch being completed, the time spent by the operators for materials handling between the work centres. This time reduction results in a substantial total cost reduction for the company.

\section{CONCLUSIONS AND IMPLICATIONS}

Digital Factory approach provides a big support for the decision-making process by means of complete representation of the manufacturing process as well as manufacturing layout, enabling them to inspect and walk around the rendered factory plant 3D model. 
Table III: Simulation outputs related to production time spent in each work station.

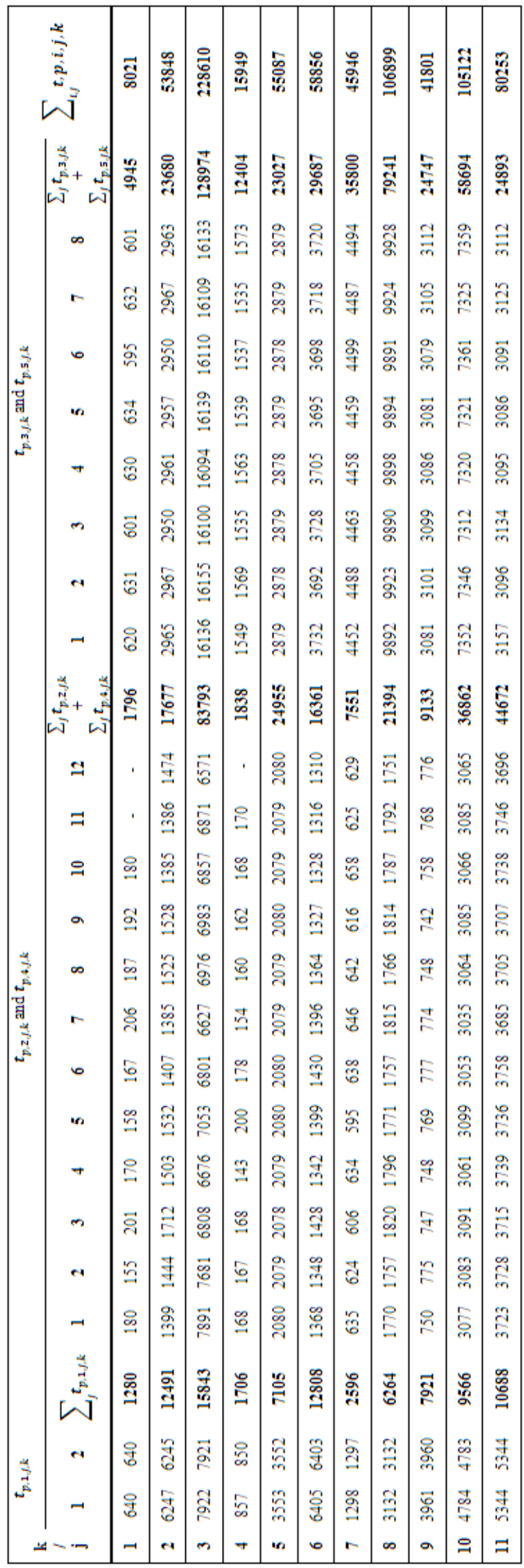


Table IV: Results comparison between the total time $\left(T_{R}\right)$ required in the 'as is' scenario $S_{R}$ and the production time in the scenario simulated $S_{S}$ in each workstation.

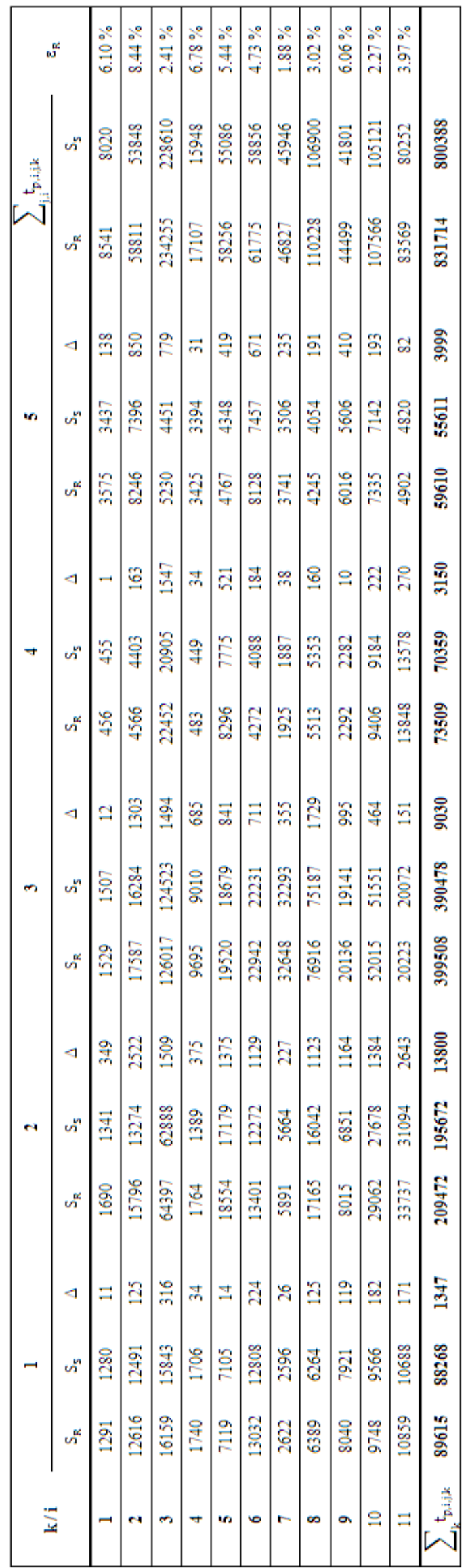


Table V: Results comparison between the total time required in 'as is' scenario $S_{R}$ and the total time required in the scenario simulated $S_{S}$, obtained adding the amount of time spent in queue $\left(\Delta=T-\left(\sum_{i} t_{p, i, k}+\sum_{i} t_{q, i, k}\right)\right) ; \varepsilon_{T}$ represents the total percentage of time saving.

\begin{tabular}{|cccc|c|c|c|}
\hline & $\boldsymbol{S}_{\boldsymbol{R}}$ & \multicolumn{2}{|c|}{$\boldsymbol{S}_{\boldsymbol{S}}$} & \multirow{\Delta}{*}{$\begin{array}{c}\Delta \\
\text { [minutes] }\end{array}$} & $\begin{array}{c}\Delta \\
\text { [hours] } \\
\text { (rounded) }\end{array}$ & $\varepsilon_{\boldsymbol{T}}$ \\
\hline $\mathbf{1}$ & $\boldsymbol{T}$ & $\sum_{\boldsymbol{i}} \boldsymbol{t}_{\boldsymbol{p}, \boldsymbol{i}, \boldsymbol{k}}$ & $\sum_{\boldsymbol{i}} \boldsymbol{t}_{\boldsymbol{q}, \boldsymbol{i}, \boldsymbol{k}}$ & & & \\
\hline $\mathbf{2}$ & 5541 & 8021 & 55 & 465 & 8 & $6.09 \%$ \\
\hline $\mathbf{3}$ & 234255 & 228610 & 93 & 5552 & 93 & $2.37 \%$ \\
\hline $\mathbf{4}$ & 17107 & 15949 & 54 & 1104 & 18 & $6.45 \%$ \\
\hline $\mathbf{5}$ & 58256 & 55087 & 103 & 3066 & 51 & $5.26 \%$ \\
\hline $\mathbf{6}$ & 61775 & 58856 & 128 & 2791 & 47 & $4.52 \%$ \\
\hline $\mathbf{7}$ & 46827 & 45946 & 93 & 788 & 13 & $1.68 \%$ \\
\hline $\mathbf{8}$ & 110228 & 106899 & 97 & 3232 & 54 & $2.93 \%$ \\
\hline $\mathbf{9}$ & 44499 & 41801 & 95 & 2603 & 43 & $5.85 \%$ \\
\hline $\mathbf{1 0}$ & 107566 & 105121 & 159 & 2286 & 38 & $2.13 \%$ \\
\hline $\mathbf{1 1}$ & 83569 & 80253 & 137 & 3179 & 53 & $3.80 \%$ \\
\hline$\sum$ & $\mathbf{8 3 1 4 3 4}$ & $\mathbf{8 0 0 3 9 1}$ & $\mathbf{1 1 2 2}$ & $\mathbf{2 9 9 2 1}$ & $\mathbf{4 9 9}$ & \\
\hline
\end{tabular}

This paper explores one of the several aspects assessed by the Digital Factory implementation approach. In this paper a proposal of a layout reconfiguration and a technological solution for the parts feeding system of the industrial plant has been analysed in order to reduce the production lead times using simulation. Furthermore simulation assists engineers and managers to find and analyse opportunities for improvements related to capacity, work-in-process flow, labour allocation, new product development and many other manufacturing issues.

The simulation results reveal that the new production system performances are definitely better than the real ones. In particular, the introduction of the conveyor system allows eliminating the waiting time spent for the batch being completed and the time spent by the operators for materials handling between the work centres. Total time reduction depends from individual orders, these values ranges from 1.6 to $8.6 \%$.

This time reduction results in a substantial total cost reduction for the company. The reduced working hours will be around 500 and considering the average hourly cost of an employee is $14.2 €$ the company will save approximately $7.100 €$. Moreover the reduced lead time allows company to acquire new orders and new customers.

\section{REFERENCES}

[1] Chambers, S. (1992). Flexibility in the Context of Manufacturing Strategy, Voss, C. A. (Ed.), Manufacturing Strategy - Process and Content, Chapman \& Hall, London, 283-295

[2] Telgen, D.; van Moergestel, L.; Puik, E.; Streng, A.; Scheefhals, R.; Bakker, T.; Hustinx, A.; van den Brink, L.; Meyer, J. (2014). Hierarchical management of a heterarchical manufacturing grid, Proceedings of the $24^{\text {th }}$ International Conference on Flexible Automation \& Intelligent Manufacturing, 825-832

[3] Gaimon, C.; Singhal, V. (1992). Flexibility and the choice of manufacturing facilities under short product life cycles, European Journal of Operational Research, Vol. 60, No. 2, 211-223, doi:10.1016/0377-2217(92)90094-P

[4] Koren, Y. (2006). General RMS Characteristics. Comparison with Dedicated and Flexible Systems, Dashchenko, A. I. (Ed.), Reconfigurable Manufacturing Systems and Transformable Factories, Springer, Berlin, 27-45, doi:10.1007/3-540-29397-3 3 
[5] Beckman, S. L. (1990). Manufacturing flexibility: The next source of competitive advantage, Moody, P. E. (Ed.), Strategic Manufacturing: Dynamic New Directions for the 1990s, Dow Jones-Irwin, Homewood, 107-132

[6] De Meyer, A.; Nakane, J.; Miller, J. G.; Ferdows, K. (1989). Flexibility: The next competitive battle the manufacturing futures survey, Strategic Management Journal, Vol. 10, No. 2, 135-144, doi: $10.1002 / \mathrm{smj} .4250100204$

[7] Goldhar, J. D.; Jelinek, M. (1983). Plan for economies of scope, Harvard Business Review, Vol. 61, No. 6, 141-148

[8] Zelenovic, D. M. (1982). Flexibility - a condition for effective production systems, International Journal of Production Research, Vol. 20, No. 3, 319-337, doi:10.1080/00207548208947770

[9] Gregor, M.; Medvecky, S.; Matuszek, J.; Stefanik, A. (2009). Digital Factory, Journal of Automation, Mobile Robotics \& Intelligent Systems, Vol. 3, No. 3, 123-132

[10] Carrie, A. (1988). Simulation of Manufacturing Systems, John Wiley \& Sons, New York

[11] Wy, J.; Jeong, S.; Kim, B.-I.; Park, J.; Shin, J.; Yoon, H.; Lee, S. (2011). A data-driven generic simulation model for logistics-embedded assembly manufacturing lines, Computers \& Industrial Engineering, Vol. 60, No. 1, 138-147, doi:10.1016/j.cie.2010.10.011

[12] Westkämper, E. (2007). Digital manufacturing in the global era, Cunha, P. F.; Maropoulos, P. G. (Eds.), Digital Enterprise Technology: Perspectives and Future Challenges, Springer, New York, 3-14

[13] Kuehn, W. (2006). Digital factory - integration of simulation enhancing the product and production process towards operative control and optimisation, International Journal of Simulation: Systems, Science and Technology, Vol. 7, No. 7, 27-39

[14] Wörn, H.; Frey, D.; Keitel, J. (2000). Digital factory - planning and running enterprises of the future, $26^{\text {th }}$ Annual Conference of the IEEE Industrial Electronics Society, Vol. 2, 1286-1291

[15] Ackermann, J.; Börner, F.; Hopf, H.; Horbach, S.; Müller, E. (2013). Approaches for planning and operation of adaptable factories, International Journal of Production Research, Vol. 51, No. 15, 4618-4629, doi:10.1080/00207543.2013.783243

[16] Reddy, B.S.P.; Rao, C.S.P. (2011). Flexible manufacturing systems modelling and performance evaluation using Automod, International Journal of Simulation Modelling, Vol. 10, No. 2, 78-90, doi:10.2507/IJSIMM10(2)3.176

[17] Gawroński, T. (2012). Optimization of setup times in the furniture industry, Annals of Operations Research, Vol. 201, No. 1, 169-182, doi:10.1007/s10479-012-1233-Z

[18] Hafezalkotob, A.; Ketabian, H.; Rahimi, H. (2014). Balancing the production line by the simulation and statistics techniques: A case study, Research Journal of Applied Sciences, Engineering and Technology, Vol. 7, No. 4, 754-763

[19] Michalos, G.; Fysikopoulos, A.; Makris, S.; Mourtzis, D.; Chryssolouris, G. (2015). Multi criteria assembly line design and configuration - An automotive case study, CIRP Journal of Manufacturing Science and Technology, Vol. 9, 69-87, doi:10.1016/j.cirpj.2015.01.002

[20] Rekiek, B.; Dolgui, A.; Delchambre, A.; Bratcu, A. (2002). State of art of optimization methods for assembly line design, Annual Reviews in Control, Vol. 26, No. 2, 163-174, doi:10.1016/S1367-5788(02)00027-5

[21] Battini, D.; Faccio, M.; Persona, A.; Sgarbossa, F. (2009). Design of the optimal feeding policy in an assembly system, International Journal of Production Economics, Vol. 121, No. 1, 233 254, doi:10.1016/j.ijpe.2009.05.016

[22] Gogouvitis, X. V.; Vosniakos, G.-C. (2015). Construction of a virtual reality environment for robotic manufacturing cells, International Journal of Computer Applications in Technology, Vol. 51, No. 3, 173-184, doi:10.1504/IJCAT.2015.069331

[23] Mourtzis, D.; Papakostas, N.; Mavrikios, D.; Makris, S.; Alexopoulos, K. (2015). The role of simulation in digital manufacturing: applications and outlook, International Journal of Computer Integrated Manufacturing, Vol. 28, No. 1, 3-24, doi:10.1080/0951192X.2013.800234

[24] Eklund, J. A. E. (1995). Relationships between ergonomics and quality in assembly work, Applied Ergonomics, Vol. 26, No. 1, 15-20, doi:10.1016/0003-6870(95)95747-N

[25] Eklund, J. (1997). Ergonomics, quality and continuous improvement - conceptual and empirical relationships in an industrial context, Ergonomics, Vol. 40, No. 10, 982-1001, doi: $\underline{10.1080 / 001401397187559}$ 
[26] Drury, C. G. (2000). Global quality: linking ergonomics and production, International Journal of Production Research, Vol. 38, No. 17, 4007-4018, doi:10.1080/00207540050204876

[27] Battini, D.; Faccio, M.; Persona, A.; Sgarbossa, F. (2011). New methodological framework to improve productivity and ergonomics in assembly system design, International Journal of Industrial Ergonomics, Vol. 41, No. 1, 30-42, doi:10.1016/j.ergon.2010.12.001

[28] Ecklund, D. K. (2010). Warehousing efficiency and effectiveness in the supply chain process, Supply Chain Management Review, October 2010

[29] De Carlo, F.; Arleo, M. A.; Borgia, O.; Tucci, M. (2013). Layout design for a low capacity manufacturing line: A case study, International Journal of Engineering Business Management, Special Issue on Innovations in Fashion Industry, Vol. 5, 10 pages, doi:10.5772/56883

[30] Singh, A. P.; Yilma, M. (2013). Production floor layout using systematic layout planning in can manufacturing company, International Conference on Control, Decision and Information Technologies (CoDIT 2013), Hammamet, 822-828

[31] Wöhlke, G.; Schiller, E. (2005). Digital planning validation in automotive industry, Computers in Industry, Vol. 56, No. 4, 393-405, doi:10.1016/j.compind.2005.01.010

[32] Liu, X.-G.; Li, X.-S. (2015). Application of virtual digital factory technology to layout simulation of foundry plant, Zhuzao/Foundry, Vol. 64, No. 6, 543-545

[33] Rodič, B.; Kanduč, T. (2015). Optimisation of a complex manufacturing process using discrete event simulation and a novel heuristic algorithm, International Journal of Mathematical Models and Methods in Applied Sciences, Vol. 9, 320-329

[34] Ficko, M.; Palcic, I. (2013). Designing a layout using the modified triangle method, and genetic algorithms, International Journal of Simulation Modelling, Vol. 12, No. 4, 237-251, doi:10.2507/IJSIMM12(4)3.244

[35] Dias, L. M. S.; Pereira, G. A. B.; Vik, P.; Oliveira, J. A. (2014). Layout and process optimisation: using computer-aided design (CAD) and simulation through an integrated systems design tool, International Journal of Simulation and Process Modelling, Vol. 9, No. 1-2, 46-62, doi:10.1504/IJSPM.2014.061437

[36] Edis, R. S.; Kahraman, B.; Araz, O. U.; Özfirat, M. K. (2011). A facility layout problem in a marble factory via simulation, Mathematical and Computational Applications, Vol. 16, No. 1, 97-104

[37] Hammad, A. A.; Salem, O.; Hastak, M.; Syal, M. (2008). Decision support system for manufactured housing facility layout, Journal of Architectural Engineering, Vol. 14, No. 2, 3646, doi:10.1061/(ASCE) 1076-0431(2008)14:2(36)

[38] Tearwattanarattikal, P.; Namphacharoen, S.; Chamrasporn, C. (2008). Using ProModel as a simulation tools to assist plant layout design and planning: Case study plastic packaging factory, Songklanakarin Journal of Science and Technology, Vol. 30, No. 1, 117-123

[39] Westkämper, E.; von Briel, R. (2001) Continuous improvement and participative factory planning by computer systems, CIRP Annals - Manufacturing Technology, Vol. 50, No. 1, 347352, doi:10.1016/S0007-8506(07)62137-4 